\title{
Structural relaxation of dense crown optical glass and soda-lime-silicate glass via Raman spectroscopy
}

\author{
Tatsuya FUKUDA ${ }^{\dagger}$ and Jun MATSUOKA* \\ Mitsue Mold Engineering Co., Ltd., University of Shiga prefecture \\ *University of Shiga prefecture
}

Fictive temperature dependence of refractive index, density, and Raman spectra of commercial dense crown optical glass widely used for lens production is investigated. It is found that the main peak in Raman spectra shifts higher with increasing the fictive temperature. As well as density and refractive index, this peak position has linear relationship with the fictive temperature. Relaxation of Raman spectra is similar with that of refractive index, and they are different from that of density. For the comparison, one commercial soda-lime-silicate glass is investigated as well as dense crown optical glass. Raman spectrum of this glass shifts lower as the fictive temperature. The difference between each relaxation time is less than that of dense crown optical glass.

(C)2013 The Ceramic Society of Japan. All rights reserved.

Key-words : Dense crown optical glass, Raman spectroscopy, Fictive temperature, Soda-lime-silicate glass, Structural relaxation

[Received June 14, 2012; Accepted October 18, 2012]

\section{Introduction}

Recently, glass molding press method is widely applied for glass lens production. ${ }^{1)}$ This method causes the structural change of optical glass due to heat treatment process. Therefore it is necessary to understand the characteristics of structural relaxation of each optical glass. Especially, knowledge about the relationship between refractive index relaxation and relaxation of other properties is important.

To investigate the structure and structural change, Raman spectroscopy is one of the most useful methods. It is widely used not only for structural analysis but also for the analysis of the relationship between spectra and fictive temperature.

For silica glass, it is well known that the intensity of so-called defect line at 495 and $605 \mathrm{~cm}^{-12)}$ rises with increasing fictive temperature. For $\mathrm{Na}_{2} \mathrm{O}-\mathrm{SiO}_{2}$ glass, it was reported that the change of the ratio of $Q^{2}$ species to $Q^{3}$ causes the change of the peak position of Raman spectrum at $1100 \mathrm{~cm}^{-1}$.) For soda-limesilicate glass, similar results were obtained. So it is possible to estimate the non-bonding oxides ratio via curve separation technique of Raman spectrum around $1100 \mathrm{~cm}^{-1}$.) In addition, for soda-lime-silicate glass, the relationship between the peak position of Raman spectrum and fictive temperature was studied. ${ }^{5)}$

For more complicated glasses, there are not many studies about Raman spectra, because it is difficult to assign their bands. But recently, the relation between Raman spectra and glass structure of boro-silicate, alumino-silicate and other complicated systems has been clarified by using nuclear magnetic resonance (NMR). ${ }^{6,7)}$

In this study, one of the commercial dense crown optical glasses and a soda-lime-silicate glass are chosen for investigation. The main system of this dense crown optical glass is aluminoboro-silicate. This type of optical glass is widely used for camera lens and many companies produce similar glasses. ${ }^{8)}$ Soda-limesilicate glass is also widely used in our life. So it is beneficial to

\footnotetext{
Corresponding author: T. Fukuda; E-mail: fukuda@mitue.co.jp
}

obtain knowledge of their characteristics. In addition, as these two glasses have very different compositions, the comparison of them should be very interesting. In this study, the change of the Raman spectra of these glasses with the change of fictive temperature is investigated.

For borate glass, it is known that the addition of alkali cations or fictive temperature change causes the change of coordination number of boron. ${ }^{9)}$ It is reported that the coordination number change of boron in alumino-boro-silicate glass caused by temperature or fictive temperature change was observed via nuclear magnetic resonance (NMR). ${ }^{7)}$ So the coordination number change of boron was considered in this study.

On the other hand, there are many studies focused on the relaxation characteristics of physical properties especially about silicate glass. For example, after examining many kinds of silicate glasses, Webb et al. concluded that volume and enthalpy relaxation have the same mechanism including the exchange of $\mathrm{Si}-\mathrm{O}$ bond. ${ }^{10)}$ In addition, Sasabe et al. reported that the relaxation time of refractive index and that of enthalpy are same in sodalime-silicate glass. ${ }^{11)}$ But at the same time, Webb et al. described that there was a little difference between relaxation characteristics of nuclear magnetic resonance (NMR) spectra and that of enthalpy and volume. So they pointed out that the relaxation characteristics of each property should be observed under constant temperature. ${ }^{10)}$ Scherer reported that there is a difference between the refractive index relaxation and enthalpy relaxation. ${ }^{12)}$

These results indicate that each property might have different relaxation characteristics. And more studies are needed to clarify this possibility. So relaxation characteristics of volume, refractive index and Raman spectrum of two types of glasses were investigated and compared to each other.

\section{Experimental procedure}

\subsection{Glass samples}

Two types of glass were chosen. Glass A is one of commercial dense crown optical glass. This glass has complicated composition and its main network system is alumino-boro-silicate. It 
Table 1. Composition and glass transition temperature of samples

\begin{tabular}{ccc}
\hline & Main composition (mol \%) & $\begin{array}{c}\text { Glass transition } \\
\text { temperature }(\mathrm{K})\end{array}$ \\
\hline Glass A & $\begin{array}{c}46 \mathrm{SiO}_{2} \cdot 2 \mathrm{Al}_{2} \mathrm{O}_{3} \cdot 37 \mathrm{~B}_{2} \mathrm{O}_{3} \cdot \\
11 \mathrm{BaO}+\text { others }\end{array}$ & 778 \\
Glass B & $\begin{array}{c}72 \mathrm{SiO}_{2} \cdot 1 \mathrm{Al}_{2} \mathrm{O}_{3} \cdot 12 \mathrm{Na}_{2} \mathrm{O} . \\
8 \mathrm{CaO} \cdot 6 \mathrm{MgO}+\text { others }\end{array}$ & 818 \\
\hline
\end{tabular}

Table 2. Heat treatment condition of quenched samples

\begin{tabular}{lcrrrrrrr}
\hline & Annealing & 699 & 719 & 739 & 759 & 779 & 799 & \\
Glass A & temperature (K) & & & & & & \\
& Holding time (h) & 48 & 24 & 24 & 12 & 6 & 4 & \\
\hline \multirow{2}{*}{ Glass B } & Annealing & 753 & 773 & 793 & 813 & 833 & 853 & 873 \\
& temperature (K) & & & & & 4 & 4 & 4 \\
\hline
\end{tabular}

contains a large amount of barium oxide. Glass B is one of commercial soda-lime-silicate glass mainly used for windows. Their main composition and glass transition temperature measured by dilatometry method with $10 \mathrm{~K} / \mathrm{min}$ heating rate are shown in Table 1.

These samples were cut into rectangular shape. The length of each side is 11,11 , and $2.5 \mathrm{~mm}$. Sample size was determined by referring the former studies. ${ }^{13), 14)}$ Top and bottom surfaces of these samples were mirror-polished. To investigate the relationship between fictive temperature and each property, each sample was kept in the furnace at specific temperature. After keeping for certain period of time, it was dropped into water rapidly. It means that the structure of each sample was frozen at certain fictive temperature. The heat treatment condition is shown in Table 2. Using these samples, the relationship between fictive temperature and various properties was investigated.

Two electric furnaces were installed vertically along the same straight line. In order to counteract the interaction of each electric furnace, the top and bottom of the entrance of the furnaces was covered with insulation cover. Each sample was set in the upper furnace for determined time, and then moved into the lower furnace quickly. After keeping for certain time, each sample was quenched by dropping into water. These samples were used for investigating relaxation characteristics.

Temperature of the upper furnace is $778 \mathrm{~K}$, and that of the lower furnace is $718 \mathrm{~K}$ for glass A. Those for glass B are 828 , $768 \mathrm{~K}$ respectively. Keeping time in the upper furnace is four hours. It is thought to be enough for each sample to relax fully. Properties were investigated as the function of holding time to know the relaxation rate.

\subsection{Raman spectroscopy}

NRS3100 (JASCO Corporation, Japan) was used for this study. The diffraction grating with 1800 lines per mm was employed. The wavelength of excitation light was $532.1 \mathrm{~nm}$. A circular type slit with 200 micro meter diameter was used. Exposure time is $10 \mathrm{~s}$. The integration was carried out three times.

In addition, in order to evaluate its peak position, smoothing was performed. Base compensation was performed by using the straight line over $1250 \mathrm{~cm}^{-1}$. The intensity at each position was normalized by dividing by the maximum peak intensity.

\subsection{Density measurement}

Density of each sample was measured by the Archimedes method using AUW120D (Shimadzu corporation, Japan). Each sample has many cracks due to rapid cooling. So after the measurement in the air, it was put into the toluene and placed in the vacuum desiccators. The pressure was reduced to approximately $100 \mathrm{hPa}$ in order to replace the air in the cracks with toluene. Temperature of toluene and room air was monitored at all times, and the temperature dependence of the density of toluene and air was considered. Atmospheric pressure was assumed to be constant.

Measurements are performed five times.

\subsection{Refractive index measurement}

Considering that there are many cracks in the sample, measurement methods using transmitting light is difficult. In addition, it is also difficult to grind cracked samples into certain shapes. Therefore ellipsometry was employed. For this purpose, FM7700W (Otsuka Electronic corporation, Japan) was used. This equipment is rotating analyzer type. The optimum exposure time was calculated by measuring the intensity of reflecting light. Considering that the accuracy of this method is worse than that of other general system, more than twenty points of the surface were measured. Arithmetic mean value of refractive indices was calculated except the maximum and minimum values. Refractive index at a wavelength of $589.15 \mathrm{~nm}$ was discussed.

\section{Results and discussion}

\subsection{Relationship between fictive temperature and each property}

The time required to fall into the water from the electric furnace is very short, so the fictive temperature can be assumed to be equal to the holding temperature in the furnace. Figure 1 shows the relationship between each property (density and refractive index) and fictive temperature of glass A. Each property has a linear relationship with fictive temperature in this temperature range. Figure 2 shows the values of glass B in which we can find similar relationships.

Figure 3(a) shows the Raman spectrum of glass A, and Fig. 3(b) shows that of glass B. Both glasses have silicate network as their main system, so the feature of both spectra are similar to each other including prominent peak around $1000-1100 \mathrm{~cm}^{-1}$. These bands are often discussed in order to analyze $\mathrm{Q}^{\mathrm{n}}$ species.

Figure 4(a) shows the relationship between the peak position around $1100 \mathrm{~cm}^{-1}$ and fictive temperature of glass A. Peak position shifts higher with higher fictive temperature. If the band in this region consists only of $\mathrm{Si}-\mathrm{O}$ stretching vibration, it is difficult to explain this relationship because of the fact that the result indicates that the ratio of $\mathrm{Q}^{3}$ species increases as the fictive temperature. Therefore in order to analyze more precisely, the band from 830 to $1180 \mathrm{~cm}^{-1}$ was separated into five bands as shown in Fig. 5 with Gaussian curve fitting method. The band around $950 \mathrm{~cm}^{-1}$ forms the shoulder, and it is assumed to express the $\mathrm{Q}^{2}$ species. ${ }^{5)}$ The band around $1050 \mathrm{~cm}^{-1}$, which is focused in this study, consists of two bands, the band at $990 \mathrm{~cm}^{-1}$ and that around $1050 \mathrm{~cm}^{-1}$. Then area ratio of $990 \mathrm{~cm}^{-1}$ band in this region was calculated. As shown in Fig. 6, the ratio decreases with the increase in fictive temperature. On the other hand, the ratio of $1050 \mathrm{~cm}^{-1}$ band almost unchanged. Therefore the behavior of peak shift should be due to the fact that the increase of fictive temperature makes the contribution of $990 \mathrm{~cm}^{-1}$ band lower.

$\mathrm{Li}$ et al. investigated the change of Raman spectra of sodium alumino-boro-silicate glass $\left(4.76 \mathrm{Al}_{2} \mathrm{O}_{3}-19.05 \mathrm{~B}_{2} \mathrm{O}_{3}-57.14 \mathrm{SiO}_{2}-\right.$ $19 \mathrm{Na}_{2} \mathrm{O}$ ) when $\mathrm{Gd}_{2} \mathrm{O}_{3}$ added in it. ${ }^{15)}$ They described that the band around $990 \mathrm{~cm}^{-1}$ consisted of B-O vibration of four coordinated boron and $\mathrm{Q}^{2}$ unit of silicon. If this band is only caused by $\mathrm{Q}^{2}$ unit, adding $\mathrm{Gd}_{2} \mathrm{O}_{3}$ would have rise the intensity of it. But the 
(a)

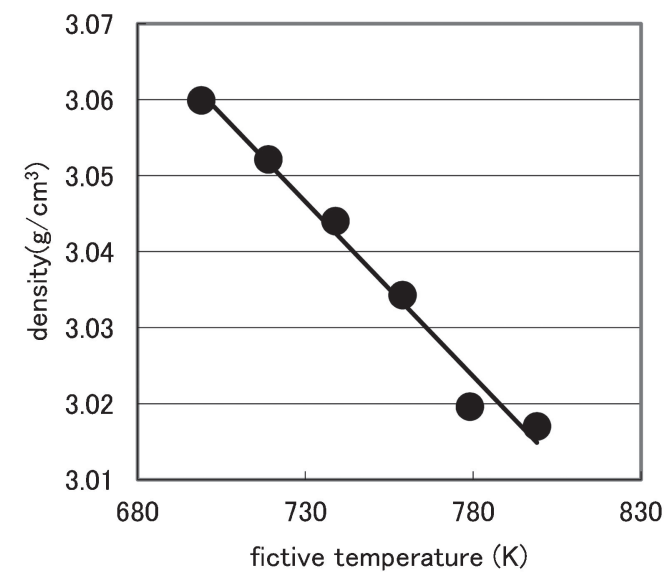

(b)

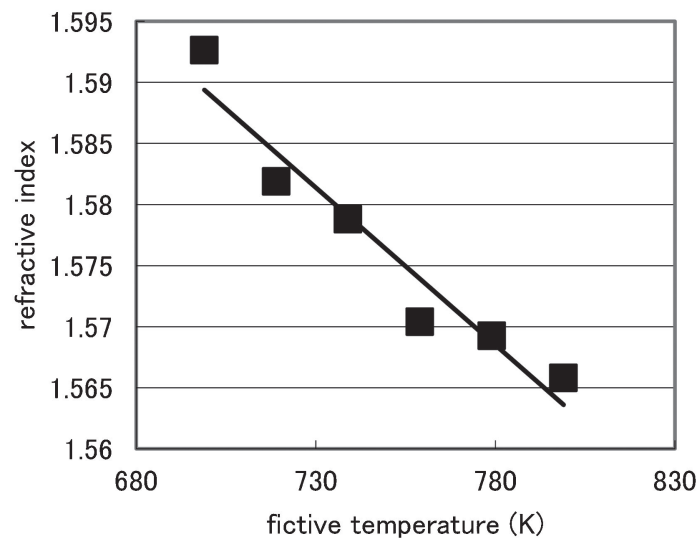

Fig. 1. Relationship between the property and fictive temperature of glass A [(a) density vs. fictive temperature, (b) refractive index (at $589.15 \mathrm{~nm}$ ) vs. fictive temperature].

(a)

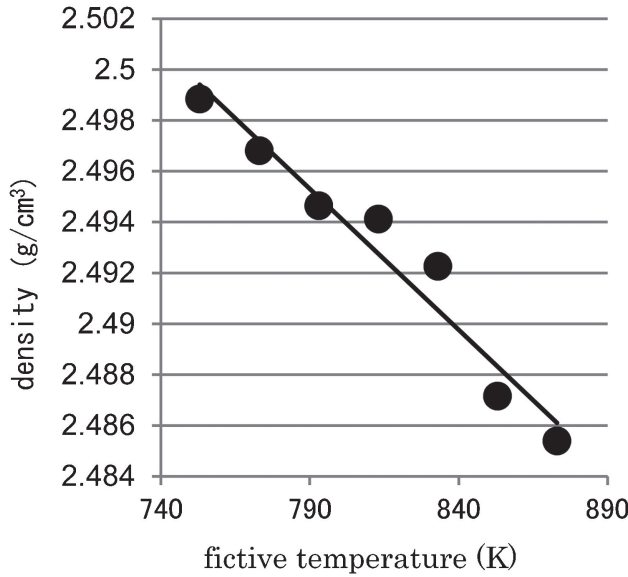

(b)

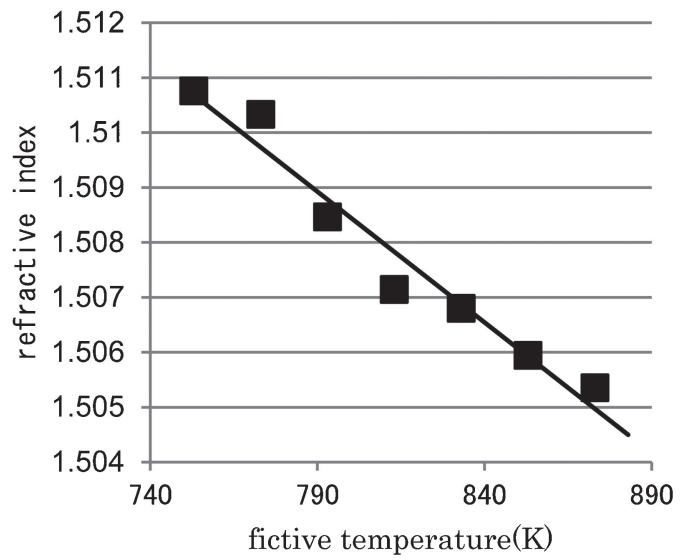

Fig. 2. Relationship between the property and fictive temperature of glass B [(a) density vs. fictive temperature, (b) refractive index (at $589.15 \mathrm{~nm})$ vs. fictive temperature].

(a)

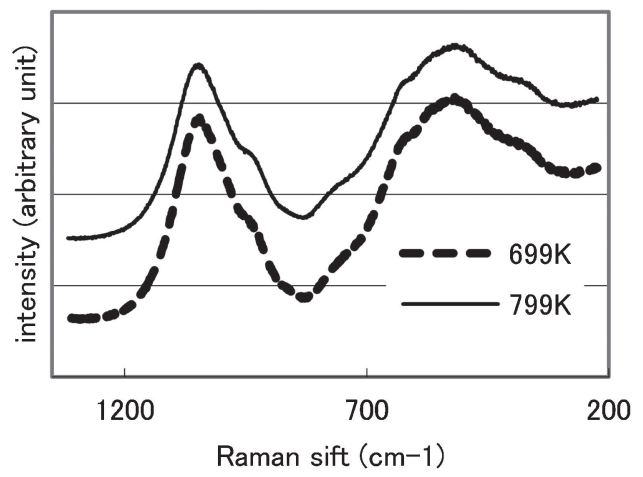

(b)

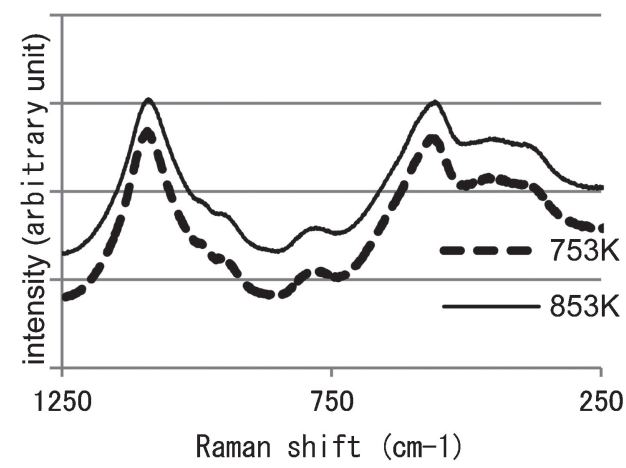

Fig. 3. Raman spectra of glass A (a) and glass B (b).

result showed the opposite direction. So they concluded that this band was mainly affected by four coordinated boron in this glass. Brown et al. analyzed the Raman spectra of alkaline-earth $\mathrm{La}_{2} \mathrm{O}_{3}-\mathrm{B}_{2} \mathrm{O}_{3}$ glass, and they concluded that the band around 990 $1000 \mathrm{~cm}^{-1}$ was caused by the stretching vibration of four coordinated B-O. ${ }^{6}$
Wu et al. investigated the coordination number of boron in alumino-boro-silicate glass by using nuclear magnetic resonance (NMR). They described that when fictive temperature rises, the coordination number changes from four to three.7)

From these results, it is reasonable to suppose that the decrease of the coordination number of boron weakens the intensity of 990 
(a)

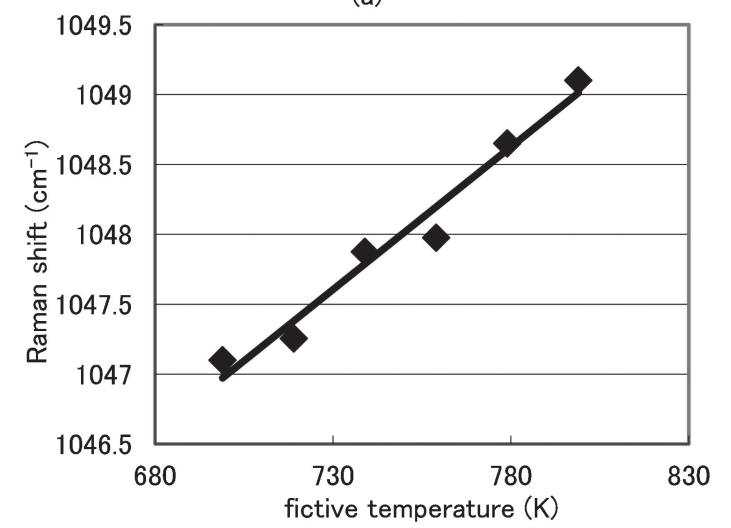

(b)

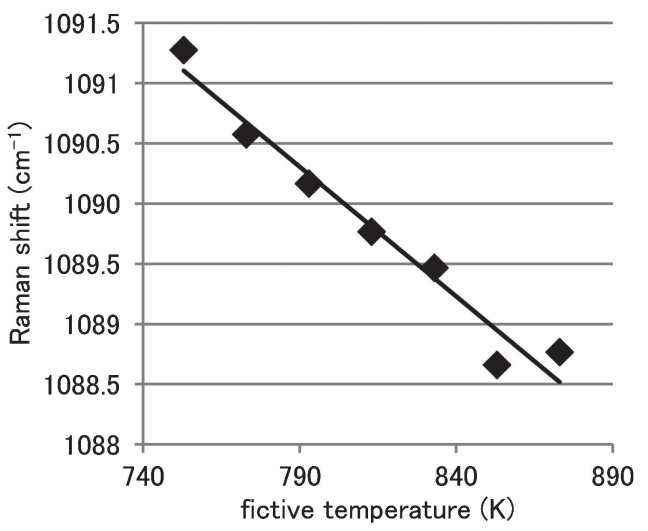

Fig. 4. Relationship between peak position of Raman spectrum and fictive temperature (a) indicates glass A and (b) indicates glass B.

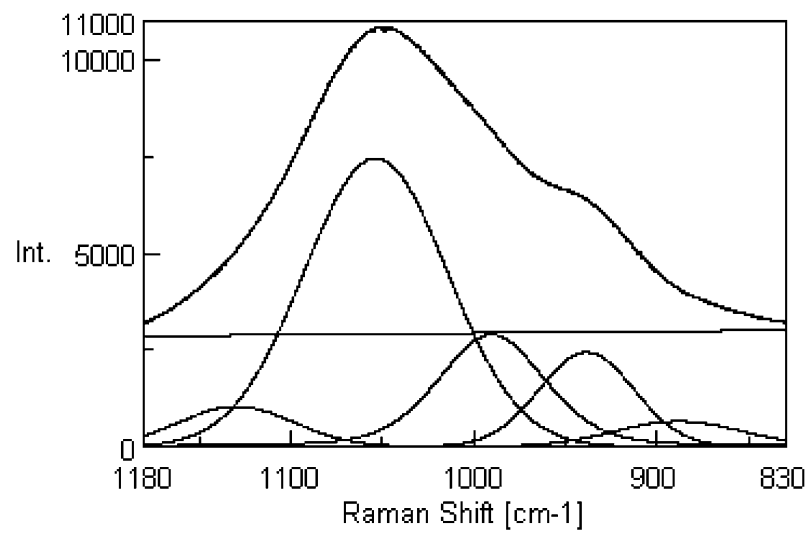

Fig. 5. Raman spectrum of glass A fitted by Gaussian curves.

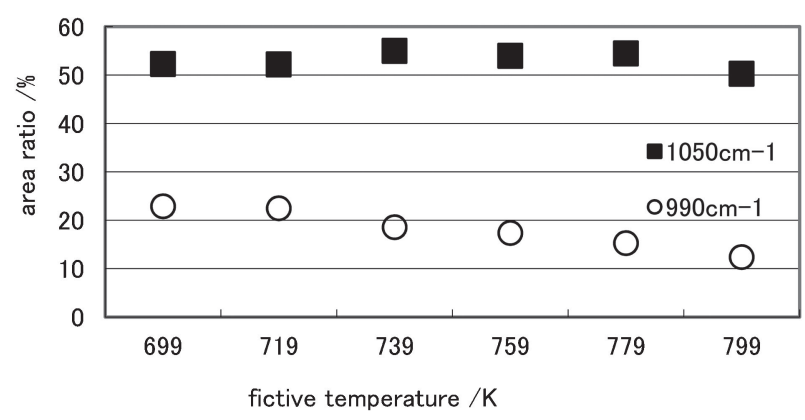

Fig. 6. Area ratio of $1050 \mathrm{~cm}^{-1}$ band and $990 \mathrm{~cm}^{-1}$ band of glass A.

$\mathrm{cm}^{-1}$ band and consequently the peak position around $1050 \mathrm{~cm}^{-1}$ shifts to higher.

As well as density and refractive index, the peak position of Raman spectrum around $1050 \mathrm{~cm}^{-1}$ has the linear relationship with fictive temperature in temperature range studied here. The relationship between fictive temperature and each property can be described in Eqs. (1)-(3), where $\mathrm{T}_{\mathrm{f}}$ indicates fictive temperature $(\mathrm{K})$.

Density $\left(\mathrm{g} / \mathrm{cm}^{3}\right)=-4.5960 \times 10^{-4} \times \mathrm{T}_{\mathrm{f}}(\mathrm{K})+3.2566$

Refractive index at $589.15 \mathrm{~nm}$

$$
=-2.578 \times 10^{-4} \times \mathrm{T}_{\mathrm{f}}(\mathrm{K})+1.699
$$

Peak position of Raman spectrum $\left(\mathrm{cm}^{-1}\right)$

$$
=2.0470 \times 10^{-2} \times \mathrm{T}_{\mathrm{f}}(\mathrm{K})+1032.7
$$

On the other hand, the band position at around $1100 \mathrm{~cm}^{-1}$ of glass B shifts lower with increasing fictive temperature as shown in Fig. 4(b). This result is consistent with previous studiess. 5),6) Parkinson et al. described that such a change of Raman spectrum is caused by the change of $\mathrm{Q}^{\mathrm{n}}$ ratio. ${ }^{4)}$ This band position change also has the linear relationship with fictive temperature like density and refractive index in the glass transition region over a range of $100 \mathrm{~K}$.

The relationship between each property and fictive temperature of glass B is expressed in Eqs. (4)-(6).

$$
\begin{aligned}
& \text { Density }\left(\mathrm{g} / \mathrm{cm}^{3}\right)=-1.1084 \times 10^{-4} \times \mathrm{T}_{\mathrm{f}}(\mathrm{K})+2.5828 \\
& \text { Refractive index at } 589.15 \mathrm{~nm} \\
& \quad=-4.760 \times 10^{-5} \times \mathrm{T}_{\mathrm{f}}(\mathrm{K})+1.547
\end{aligned}
$$

Peak position of Raman spectrum $\left(\mathrm{cm}^{-1}\right)$

$$
=-2.1525 \times 10^{-2} \times \mathrm{T}_{\mathrm{f}}(\mathrm{K})+1107.3
$$

\subsection{Structural relaxation investigation via step temperature change}

The relationship between the value of each property and holding time was investigated. The initial value and final value of each property were calculated by using Eqs. (1)-(3) for glass A and (4)-(6) for glass B. By using these initial and final values, each value was normalized. The normalized value at each holding time $\operatorname{Pn}(\mathrm{t})$ can be expressed in Eq. (7). In this equation, $\mathrm{Pi}$ means initial value, $\mathrm{Pe}$ is final value, and $\mathrm{P}(\mathrm{t})$ is the value at holding time ' $\mathrm{t}$ '.

$$
\operatorname{Pn}(\mathrm{t})=|(\mathrm{P}(\mathrm{t})-\mathrm{Pi}) /(\mathrm{Pe}-\mathrm{Pi})|
$$

The relationship between the normalized value of each property and holding time is shown in Fig. 7 (glass A) and Fig. 8 (glass B).

For glass A, it can be recognized from Fig. 7 that the relaxation time of density is shorter than that of other properties. The relaxation time of peak position of Raman spectrum is similar to that of refractive index. Glass B shows different results in Fig. 8. For this glass, the relaxation time of density is shorter than others too. But the difference is not as big as glass A. In addition, there is a little difference between Raman spectrum relaxation and refractive index relaxation.

Each relaxation time was calculated by fitting each data to the following Eq. (8), where ' $t$ ' is the holding time and $\tau$ is the relaxation time. 


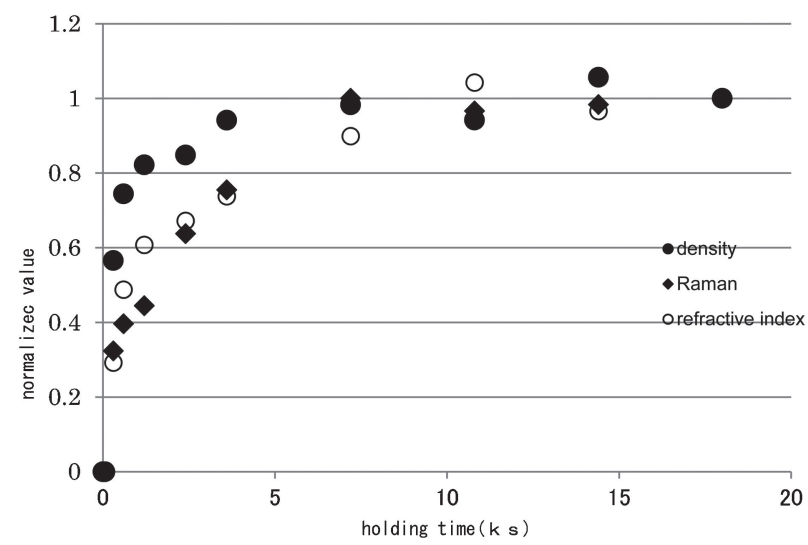

Fig. 7. Relationship between normalized each property and duration (glass A).

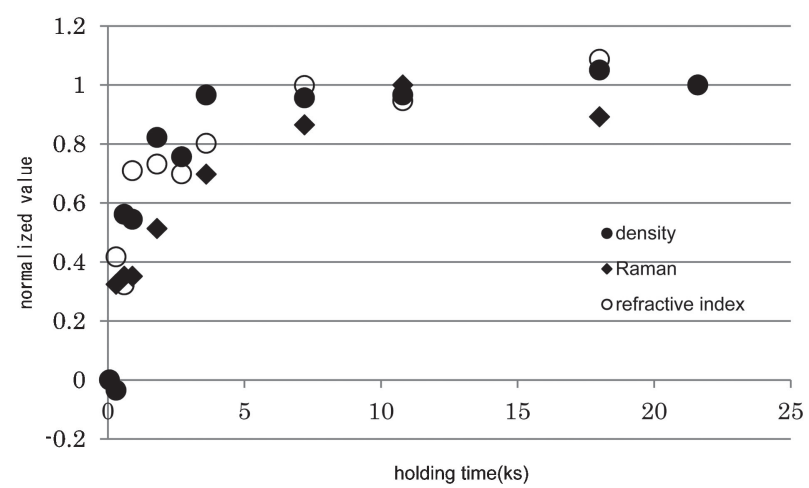

Fig. 8. Relationship between normalized each property and duration (glass B).

Table 3. Relaxation time (Ksec) of each property

\begin{tabular}{cccc}
\hline & Density & Refractive index & $\begin{array}{c}\text { Peak position of } \\
\text { Raman band }\end{array}$ \\
\hline Glass A & 6.24 & 8.52 & 8.54 \\
Glass B & 8.24 & 8.32 & 9.28 \\
\hline
\end{tabular}

$$
\operatorname{Pn}(\mathrm{t})=1-\exp (-\mathrm{t} / \tau)
$$

Results are shown in Table 3.

Change of Raman band position in glass A is caused by the change of coordination number of boron. Yano et al. investigated the structural change of soda-borate glass and found that the change in coordination number occurs suddenly at a specific temperature, in many cases, it is higher than the glass transition temperature. ${ }^{16)}$ Its result indicates that the relaxation of coordination number change of boron has longer relaxation time than that of density relaxation. That is the reason why there is large difference between the relaxation time of density and that of Raman spectrum. In addition, our result indicates that the refractive index relaxation is more affected by change of coordination number of network cation than volume change.

On the other hand, there are many studies about the structural relaxation of silicate glass. For example, Webb described that for silicate glass, the relaxation of volume and that of shear stress have the same relaxation time in relatively low viscosity range. ${ }^{17)}$ In another study, Webb investigated the relaxation characteristics of $\mathrm{NaSi}_{2} \mathrm{O}_{5}$ glass and concluded that volume, enthalpy, and shear relaxation had approximately the same relaxation time. ${ }^{18)}$
Our result of glass B is not fully consistent with these previous studies. The relaxation time of density is a little shorter than that of refractive index and Raman spectrum. In addition, the relaxation time of Raman spectrum is a little longer than that of refractive index. Webb and Knoche investigated many kinds of silicate glasses, and found that the relaxation time of $\mathrm{Si}-\mathrm{O}$ exchange observed by nuclear magnetic resonance spectroscopy (NMR) was a little longer than that of shear stress relaxation. ${ }^{10)}$ In addition, the result of Scherer's study about soda-limesilicate glass indicates that there is difference between the time of refractive index relaxation and that of enthalpy relaxation. ${ }^{12)}$ So it is possible to suppose that each property has each relaxation time.

One of the similar points of the results of glass A and B is that density relaxation has shorter relaxation time than Raman and refractive index relaxation. As the reason, it is thought that it is caused not only by the structural change like coordination number change in glass $\mathrm{A}$ or rearrangement of $\mathrm{Si}-\mathrm{O}$ network in glass B but also by shorter process like the change of bond angle.

The other similar point is that the relaxation time of refractive index is a little shorter than that of Raman spectra. Refractive index is affected by faster relaxation like density and slower relaxation like structural change indicated by Raman spectra. Therefore the relaxation time of refractive index is longer than density and shorter than Raman spectra.

\section{Conclusion}

For commercial dense crown optical glass and soda-limesilicate glass, the relationship between fictive temperature and some properties (density, refractive index, and Raman spectra) was investigated. It is found that for both glasses, each property has linear relationship with their fictive temperature.

The peak position of Raman band at around $1100 \mathrm{~cm}^{-1}$ of soda-lime-silicate glass shifts lower as the fictive temperature. But for dense crown optical glass, the peak position shifts higher as the fictive temperature. As the reason of this result, it is thought that high fictive temperature causes the decrease of the ratio of four coordinated boron.

The relaxation time of volume is shorter than that of other properties for both glasses. The difference between density relaxation time and that of others is larger in dense crown than soda-lime-silicate glass.

These results obtained in this study have two sides of useful information. Firstly, it is possible to estimate the fictive temperature of glasses by using Raman spectroscopy. Secondly, it is possible to estimate the refractive index relaxation by observing Raman spectra change for dense crown optical glass studied here.

Acknowledgement This study was partially supported by Subsidies for projects to promote the enhancement of manufacturing technology for small and medium enterprises, Japan.

\section{References}

1) A. Y. Yi and A. Jain, J. Am. Ceram. Soc., 88, 579-586 (2005).

2) A. E. Geissberger and F. L. Galeener, Phys. Rev. B, 28, 32663271 (1983).

3) J. Tan, S. Zhao, W. Wang, G. Davies and X. Mo, Mater. Sci. Eng., B, 106, 295-299 (2004).

4) B. G. Parkinson, D. Holland, M. E. Smith, C. Larson, J. Doerr, M. Affatigato, S. A. Feller, A. P. D. Howes and C. R. Scales, J. Non-Cryst. Solids, 354, 1936-1942 (2008).

5) C. Levelut, R. LeParc, A. Faivre and B. Champagnon, J. NonCryst. Solids, 352, 4495-4499 (2006). 
6) R. K. Brown and D. R. Tallant, J. Am. Ceram. Soc., 79, 24102416 (1996).

7) J. Wu and J. F. Stebbins, J. Non-Cryst. Solids, 356, 2097-2108 (2010).

8) G. Gliemeroth, "Light through optical glass", Schott Information 4, Mainz (1981).

9) R. J. Araujo, Phys. Chem. Glasses, 21, 193-196 (1980).

10) S. Webb and R. Knoche, Chem. Geol., 128, 165-183 (1996).

11) H. Sasabe, M. A. Debolt, P. B. Macedo and C. T. Moynihan, Proc. 11th Int. Congr. on glass, Prague, 1 (1977) pp. 339-348.

12) G. W. Schere, J. Am. Ceram. Soc., 67, 504-511 (1984).
13) M. Hara and S. Suetoshi, Rep. Res. Lab. Asahi Glass Co. Ltd., 5, 126-135 (1955).

14) V. Haken, O. Humbach, S. Orther and H. Fabian, J. Non-Cryst. Solids, 265, 9-18 (2000).

15) H. Li, Y. Su and D. M. Strachan, J. Non-Cryst. Solids, 292, 167-176 (2001).

16) T. Yano, N. Kunimine, S. Shibata and M. Yamane, J. NonCryst. Solids, 321, 147-156 (2003).

17) S. Webb, Chem. Geol., 96, 449-457 (1992).

18) S. Webb, Am. Mineral., 76, 1449-1454 (1991). 